\title{
January temperature anomalies over Northeast China and precursors
}

\author{
LI Chao ${ }^{2,3^{*}} \&$ ZHANG QingYun ${ }^{1,2^{*}}$ \\ ${ }^{1}$ State Key Laboratory of Numerical Modeling for Atmospheric Sciences and Geophysical Fluid Dynamics, Institute of Atmospheric Physics, \\ Chinese Academy of Sciences, Beijing 100029, China; \\ ${ }^{2}$ International Center for Climate and Environment Sciences, Institute of Atmospheric Physics, Chinese Academy of Sciences, \\ Beijing 100029, China; \\ ${ }^{3}$ Graduate University of the Chinese Academy of Sciences, Beijing 100049, China
}

Received July 6, 2012; accepted August 7, 2012; published online September 25, 2012

\begin{abstract}
This paper analyzes the large-scale atmospheric circulation characteristics of anomalous cases of January temperatures that occurred in Northeast China during 1960-2008 and precursory oceanic conditions. The January monthly mean surface air temperature (SAT) anomalies and the duration of low temperature are used to define temperature anomaly cases. The anomalous cyclonic circulation over northeast Asia strengthens the northerly flow in cold Januarys, while the anomalous anticyclonic circulation weakens the northerly flow in the warm Januarys. The negative (positive) North Pacific sea surface temperature anomaly (SSTA) and increased (decreased) sea ice concentration in the Barents-Kara seas in the preceding month are probably linked to the cyclonic (anticyclonic) circulation pattern over northeast Asia in the cold (warm) cases. Further analyses indicate that the preceding oceanic conditions play distinct roles in the SAT anomalies over Northeast China on different time scales. Strong relationships exist between North Pacific SSTA and the SAT in Northeast China on the interannual time scale. On the other hand, the sea ice concentration is more closely associated with the interdecadal variations of SAT in Northeast China.
\end{abstract}

surface air temperature in Northeast China, duration of low temperature, sea surface temperature, sea ice concentration, cross-spectral

Citation: $\quad$ Li C, Zhang Q Y. January temperature anomalies over Northeast China and precursors. Chin Sci Bull, 2013, 58: 671-677, doi: 10.1007/s11434$012-5467-6$

A number of extremely regional cold winters have occurred during a period marked by an overall trend in warming [1,2]. Understanding wintertime climate variability in Northeast China (NEC) is crucial for improving regional climate predictability. Severe low temperatures could lead to the collapse of electric networks and seriously damage highway and railway transportation systems. The persistence of low temperatures would also greatly increase the demand for fuel. Thus, much research has investigated the variability of wintertime temperature anomalies and their precursors. Because of the mutual influences of tropical and extratropical atmospheric systems, the climate over NEC is characterized by many complex features $[3,4]$.

The variability of temperature in wintertime has attracted

*Corresponding authors (email: lichao@mail.iap.ac.cn; zqy@mail.iap.ac.cn) increasing attention. Many previous studies have investigated the characteristics of the East Asian winter monsoon (EAWM) (e.g. [5,6]). Wu et al. [7] reported that the EAWM has two distinct modes, the first of which is closely related to several features of the atmospheric circulation over East Asia, such as Siberian high (SH). The EAWM has a great impact on the surface air temperature (SAT) over eastern China. Nevertheless, the wintertime climate in NEC is quite different from eastern China and has some local features [8]. For example, a severe snowstorm disaster occurred in central-eastern China and the eastern part of Northwest China in January 2008, while NEC experienced a rather mild winter [9]. The wintertime SAT over NEC shows distinct variation from the other areas in China, as revealed by the second EOF mode of the monthly mean temperature [8]. Thus, the variability of the winter temperature in NEC requires further 
investigation.

A number of studies have revealed that the SAT could be affected by preceding oceanic conditions. As a result of altered atmospheric heating, the external forcing likely influences large-scale circulation, such as quasi-stationary waves, the jet stream and the storm track [10]. Some sea surface temperature (SST) anomalies could exert some influence on the wintertime circulation [11-14]. In fact, equatorial eastern Pacific SSTs are closely related to the second mode of EAWM [7]. The sea ice is another important type of external forcing [15-17]. The variation of winter sea ice extent in the Barents-Kara (B-K) seas is closely associated with that of the EU teleconnection pattern and the EAWM [18]. September Arctic sea ice concentration could provide a potential precursor for winter SH [1]. Nevertheless, the distinct climatological impacts of different external forcing mechanisms remain unclear.

The circulation anomalies are dependent on the interseasonal variations in background circulation during the wintertime [19]. Therefore, we use the January monthly mean to discuss the variations of wintertime temperature in NEC, associated circulation anomalies and some precursors on multiple time scales.

\section{Datasets and method}

The data used in the present study are from NCEP/NCAR reanalysis and are on a $2.5^{\circ} \times 2.5^{\circ}$ latitude-longitude grid [20]. Additionally, the study uses sea surface temperature (SST) data that have a horizontal resolution of $2.0^{\circ}$ latitude by $2.0^{\circ}$ longitude [21]. The sea ice concentration (SIC) data are from the Hadley Center and are on a $1.0^{\circ} \times 1.0^{\circ}$ grid [22].

We used a homogenized daily mean temperature series from 1960-2008 with 549 in situ stations, covering all of China to represent surface air temperature [23]. Some biases due to various non-natural changes have been removed from the homogenized dataset. In this paper, we calculated the monthly-mean SAT from the daily data. There are $94 \mathrm{ob-}$ servational stations chosen in NEC (Figure 1), which covers Liaoning Province, Jilin Province, Heilongjiang Province and the eastern part of Inner Mongolia Autonomous Region. The selection covers a wide area and serves to bring out large-scale features in our further analyses.

Additionally, the ECHAM5 model (T42 spectral resolution and 19 pressure levels, [24]) was applied to explore the effects of SSTA on the latter atmosphere circulation. Two pairs of experiments were conducted, one with the climatological seasonal cycle of SST (control runs), and the other with the observed SSTA added to the climatological SST (SSTA runs). The model was integrated for 21 years, and the first year was discarded as the spin-up period.

To distinguish the impact of preceding external forcing on different time scales, cross-spectral analysis was utilized. Prior to cross-spectral transform, the time series were tapered

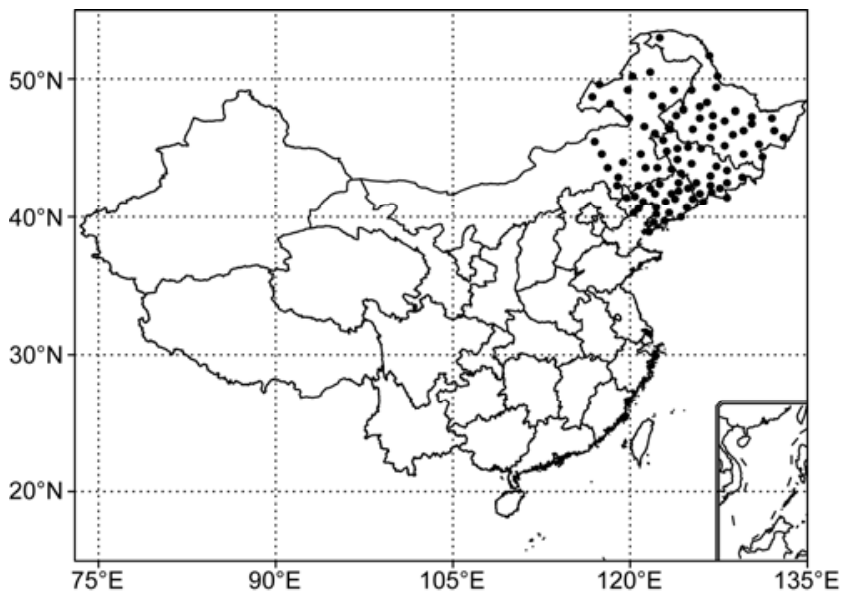

Figure 1 The spatial distribution of surface meteorological stations (94 stations) in Northeast China.

to reduce spectral leakage. The time period analyzed is during 1960-2008, which is consistent with the range of the homogenized daily mean temperature series. Here, the winter of 2008 refers to January 2008. In this study, the climatology mean is defined as the average from 1960 to 2008 , and the anomaly is the departure from this climatology mean. Two-sided Student's $t$-tests are applied to test the significance of the composites, regressions and correlation analyses.

\section{Anomalous atmospheric circulations during January temperature anomalies}

\subsection{Definition and selection of anomalous cases of January temperatures}

Anomalous cases of wintertime temperatures in NEC are selected by using the January SAT anomalies (Figure 2(a)). We define a cold case as a January SAT anomaly in NEC less than -0.9 standard deviation. The warm cases were selected as contrast cases and are defined as January SAT anomalies greater than 0.8 standard deviation. According to this definition, we selected 10 cold cases $(1960,1963,1969$, $1970,1977,1980,1985,1990,2000,2001)$ and 8 warm cases (1983, 1988, 1989, 1992, 1995, 1999, 2002, 2007). The average SAT in the cold/warm Januarys is -19.4/-13.4 degrees Celsius, and the difference exceeds a $99 \%$ confidence level. The threshold for the selection provides an adequate number of cases and avoids a loss of representative cases to the extent possible. The duration of low temperature is another concern in the wintertime. Figure 2(b) shows the number of days in January when the area-averaged SAT anomalies are less than -1.0 standard deviation. The average duration of low temperature in the cold/warm cases is 11.9/0.5 days, and the difference exceeds a 99\% confidence level. As a result, the selection has considered both the variability of SAT anomalies and the duration of low temperature. 

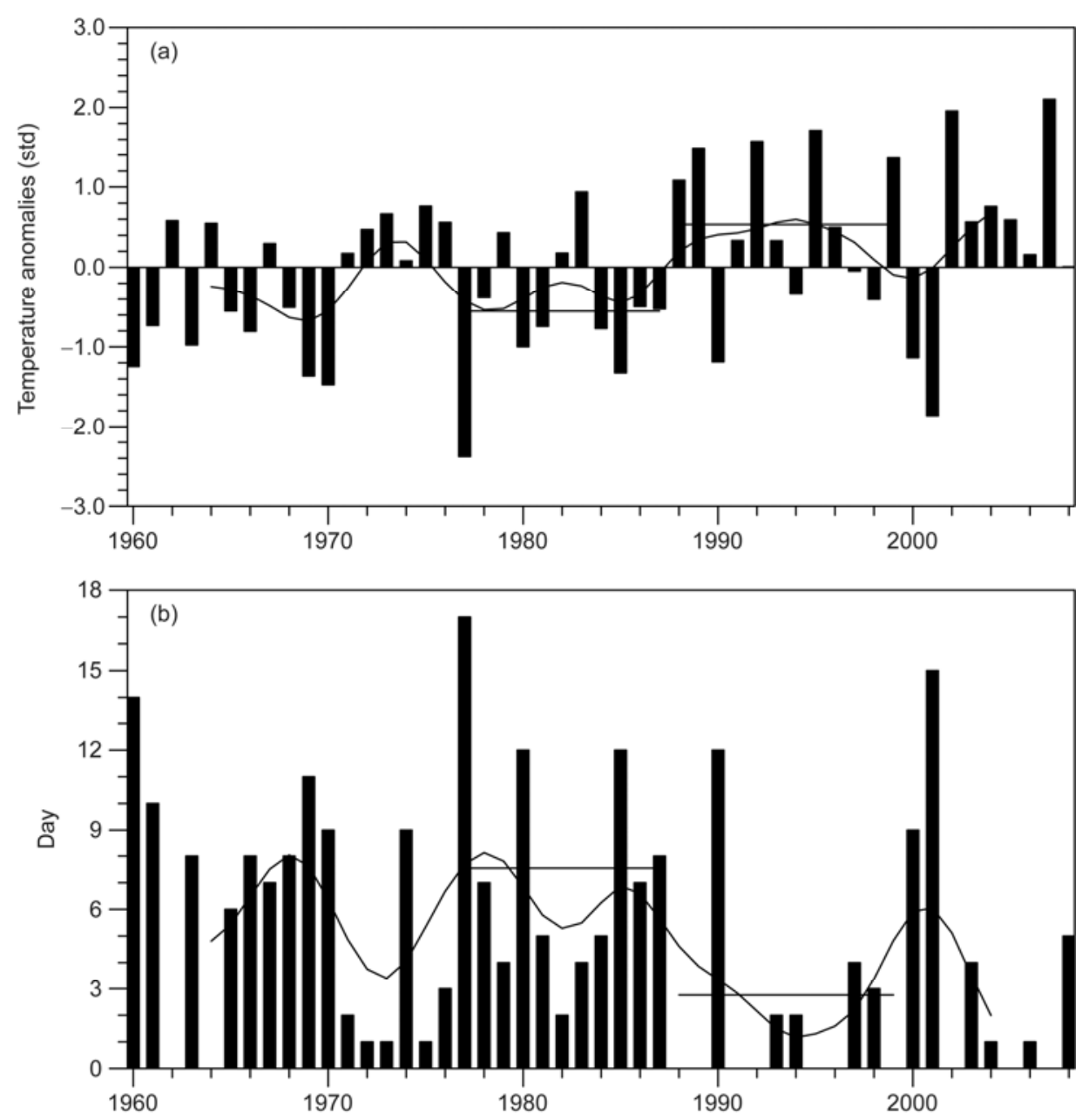

Figure 2 (a) Normalized time series (1960-2008) of January area-averaged temperature anomalies ( $\left.{ }^{\circ} \mathrm{C}\right)$ in Northeast China and (b) the number of days in January when the temperature anomalies are below 1.0 standard deviation. The thick lines represent data smoothed with a 10-year Lanczos filter. The horizontal lines indicate the average values of normalized temperature anomalies in (a) and the duration of low temperature in (b) for 1976-1987 and 1988-1999.

The high correlation coefficient $(-0.87)$ between the variability of SAT and the duration of low temperature supports the above assertion.

The SAT in NEC is characterized by not only interannual variability but also interdecadal fluctuation. The wintertime temperature in NEC experienced a significant warming during the late 1980s (Figure 2). The average SAT for the 1976-1987 (1988-1999) period is -17.6 (-15.4) degrees Celsius, and the average duration of low temperature is 7.55 (2.76) days in January. The difference between the 1976-1987 period and 1988-1999 period exceeds a 95\% confidence level in both the SAT anomalies and the duration of low temperature.

\subsection{Atmospheric circulation anomaly patterns}

The January temperature anomalies in NEC are closely connected to circulation at mid to high latitude. Figure 3 presents the January monthly mean circulation anomalies for the SAT anomaly cases.
The geopotential height anomalies at $500 \mathrm{hPa}$ in the cold cases exhibit an anomalous low over northeast Asia, and an anomalous high to the north of this region (Figure 3(a)). The cyclone anomaly patterns from the upper level to the lower level show some fairly baroclinic features. The cyclone circulation anomaly shifts southward slightly at $850 \mathrm{hPa}$ (Figure 3(c)). In line with the strengthened northerly flow from the highlatitude, the significant negative SAT anomalies can be seen over northeast Asia (Figure 3(e)).

By contrast, a 500-hPa anomalous high covers the northeast Asia-northwest Pacific region in the warm Januarys (Figure 3(b)). The south-westerly anomalies that bring warmer Pacific air masses to NEC (Figure 3(d)) are contrasted by anomalous north-easterly flows in the cold cases (Figure 3(c)). These flows produce an overall warming in all of northeast Asia (Figure 3(f)). As noted above, the wintertime temperature in NEC experienced a significant warming during the late 1980s. The circulation exhibits a similar pattern on the interdecadal time scale. An anomalous high occupied the northeast Asia-northwest Pacific region after 

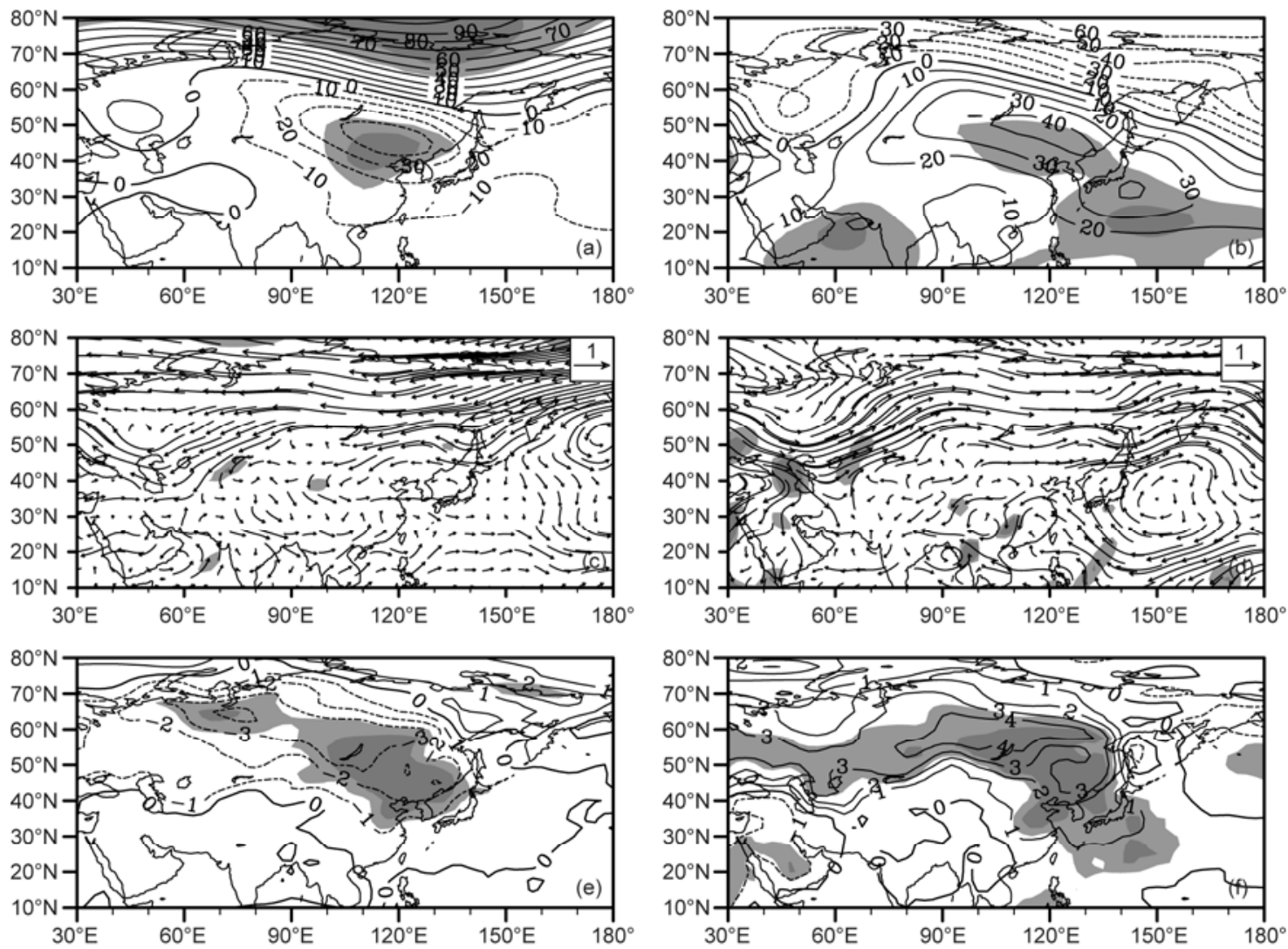

Figure 3 Composites of January $500 \mathrm{hPa}$ geopotential height anomalies (gpm) for (a) the cold cases and (b) the warm cases. (c)-(d) Same as in (a)-(b), except for the $850 \mathrm{hPa}$ wind (m/s); (e)-(f) same as in (a)-(b), except for the surface air temperature $\left({ }^{\circ} \mathrm{C}\right)$ based on the NCEP/NCAR reanalysis dataset. The dark (light) shading denotes the regions that exceed the $99 \%$ (95\%) confidence level.

1987, and the synchronous northerly flow was weakened (figure not shown).

\section{Teleconnection between January temperature anomalies and their precursors}

\subsection{Sea surface temperature anomalies in the preceding month}

The above section discussed the circulation anomaly patterns over northeast Asia that may be responsible for the variability of SAT in NEC. Going forward, it is imperative that we examine what forces cause the change in atmospheric anomalies.

Figure 4(a) presents the difference of SSTA in the preceding December between two groups of SAT anomaly cases (the warm cases minus the cold cases). The significant SSTA is mainly over the northern Pacific Ocean $\left(30^{\circ}-40^{\circ} \mathrm{N}\right.$, $150^{\circ} \mathrm{E}-180^{\circ}$ ). The cold (warm) SST is associated with the negative (positive) January SAT anomalies in NEC. To further analyze atmospheric circulation anomalies associated with the previous December SSTAs, a linear regression analysis was performed on the December SST, as shown in Figure 5(a),(c). The cold (warm) SSTs are related to the anomalous low (high) at $500 \mathrm{hPa}$ (Figure 5(a)) and strengthened (weakened) the northerly winds at $850 \mathrm{hPa}$ (Figure 5(c)) over the northeast Asia. This finding suggests that the SSTA may exert some influence on the temperature anomalies in NEC by means of the circulation anomalies over northeast Asia.

We further examine the link between the circulation anomaly patterns and the preceding northern Pacific SSTA by using the ECHAM5 model. Figure 6 shows the difference of circulation patterns between the SSTA and the control runs. After we imposed the positive northern Pacific SSTA, the modeled atmospheric responses at $500 \mathrm{hPa}$ show anomalous highs over the northeast Asia-northwest Pacific region (Figure 6(a)). The wind at $850 \mathrm{hPa}$ shows southerly anomalies (Figure 6(b)), which are fairly similar to the observation (Figure 3(d)). The northern Pacific SSTA and associated diabatic heating are located downstream of the exit region of the East Asian jet (EAJ). Li [13] argued that the anomalous transient vorticity forcing due to transient vorticity flux convergence would favor an anticyclone circulation anomaly in the north of midlatitude SSTA (see his Figure 10). Compared with the observation, the anomalous high shifts slightly southward in the SSTA runs. The climatology of the East Asian jet (EAJ) and that of storm track, simulated by ECHAM 5, are weaker than the observation [25], which may responsible for southward shift response anticyclone anomalies [26]. These results have been supported 

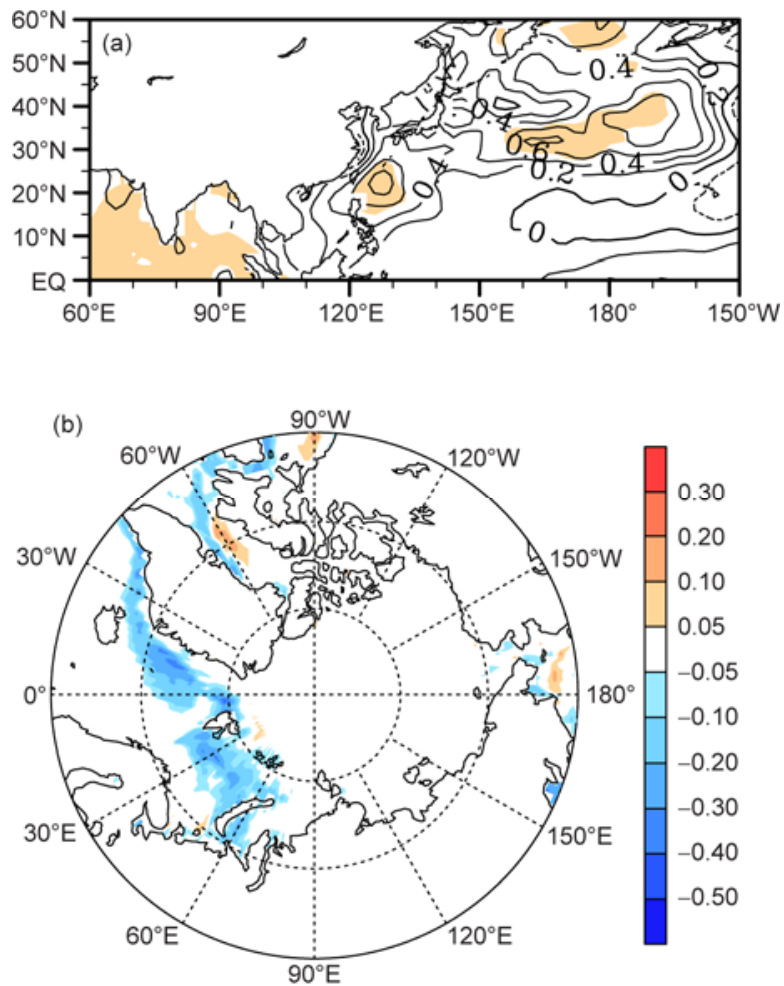

Figure 4 (a) Composite difference of the preceding December SSTA (K) means between the warm cases and the cold cases; (b) same as in (a), except for the sea ice concentration (\%). Shading in (a) is applied where the significance level exceeds $95 \%$.

by the simulation experiments and arguments of Peng and Whitaker [26].

\subsection{Sea ice anomalies in the preceding month}

Figure 4(b) displays the difference of SIC in the preceding
December between two groups of SAT anomaly cases. The sea ice anomalies differ greatly in the Barents-Kara (B-K) seas $\left(30^{\circ}-60^{\circ} \mathrm{E}, 65^{\circ}-80^{\circ} \mathrm{N}\right)$. The regression analyses show that the increased (decreased) SIC is closely related to the anomalous low (high) at $500 \mathrm{hPa}$ (Figure 5(b)) over northeast Asia and the enhanced (attenuated) northerly flow at $850 \mathrm{hPa}$ (Figure 5(d)) in the cold (warm) cases.

The sea ice reduction would cause the lower-troposphere heating over the B-K seas. Moreover, the local response to the decrease in sea ice may stem from the interplay between convectional-frictional (due to the anomalous diabatic warming and change in the surface friction conditions) and baroclinic-frictional (due to modified temperature gradients near the heat source and the change in the surface friction force) mechanisms [27]. The convectional-frictional mechanism would favor upward (convective-type) vertical motions and induce the corresponding positive cyclone-type vorticity for the SIC reduction. Owning to the modified horizontal temperature gradients, the baroclinic-frictional mechanism would always induce the anticyclone-type vorticity for the SIC reduction. The simulations of Petoukhov and Semenov [27] show that the patterns of SAT and circulation response to the SIC in B-K sectors are quite dependent on the range of the SIC. In our selection, the sea ice concentrations in most cases are less than $40 \%$, except for three cases (the SIC in 1960, 1969 and 1989 was 40.9\%, 63.0\% and 41.2\%, respectively). The average SIC for the cold/warm Januarys is $33.5 \% / 26.3 \%$. The simulation of Petoukhov and Semenov [27] revealed that the convectional-frictional effect would be greater than that of the baroclinic-frictional effect within the SIC range of $1 \%-40 \%$ and a local anomalous cyclone type atmospheric response to the SIC reduction. The local response acts as the original pacemaker for a whole $\mathrm{NH}$ atmospheric circulation rearrangement. The patterns of
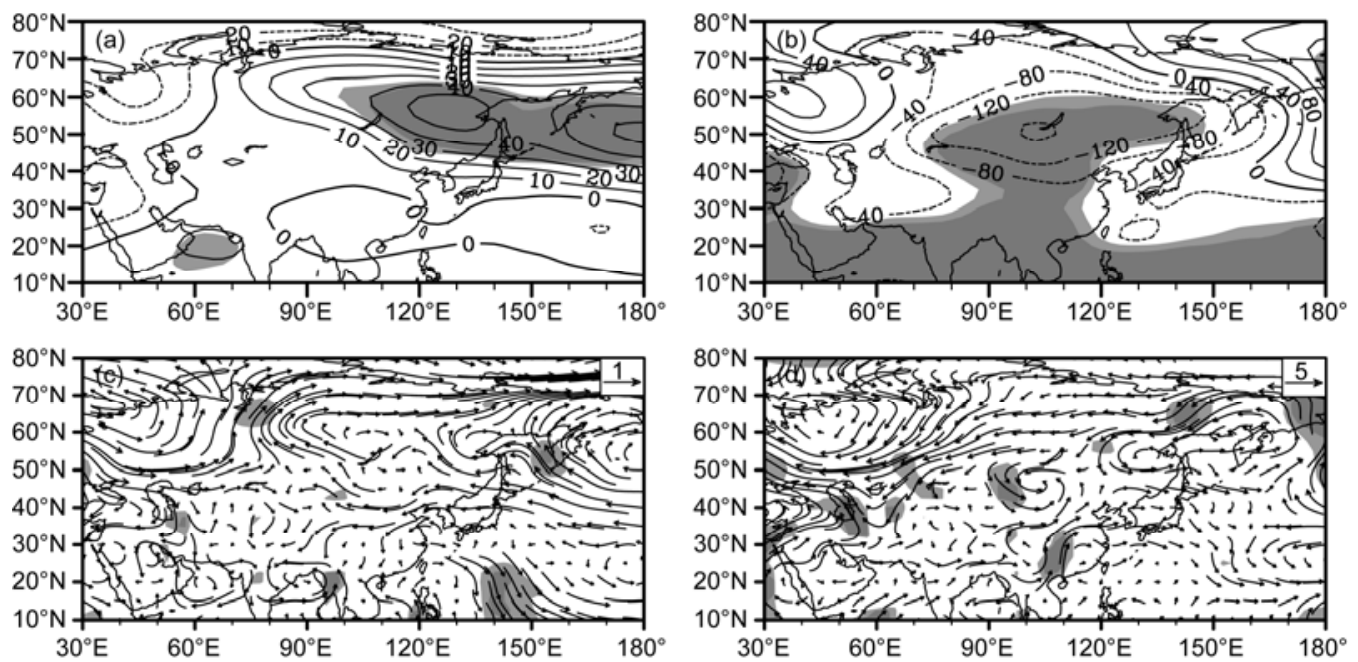

Figure 5 Geopotential height (gpm) patterns at $500 \mathrm{hPa}$ regressed by (a) the SSTA (K) over the northern Pacific and (b) the sea ice concentration (\%) in the Barents-Kara seas during 1960-2008, (c)-(d) same as in (a)-(b), except for the regressed $850 \mathrm{hPa}$ wind (m/s). The contour intervals are 10 gpm in (a) and $40 \mathrm{gpm}$ in (b). The dark (light) shading denotes the regions that exceed the $99 \%$ (95\%) confidence level. 

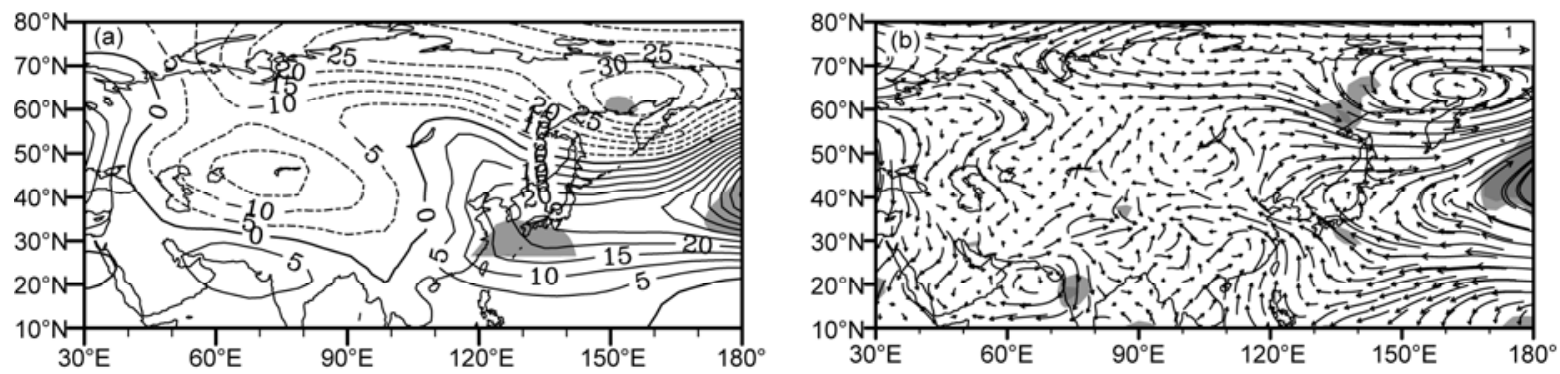

Figure 6 Simulated with ECHAM5 monthly (a) $500 \mathrm{hPa}$ geopotential height (gpm), (b) $850 \mathrm{hPa}$ horizontal wind (m/s) response to the positive northern Pacific Ocean SSTA (K). The dark (light) shading denotes the regions that exceed the 95\% (90\%) confidence level.
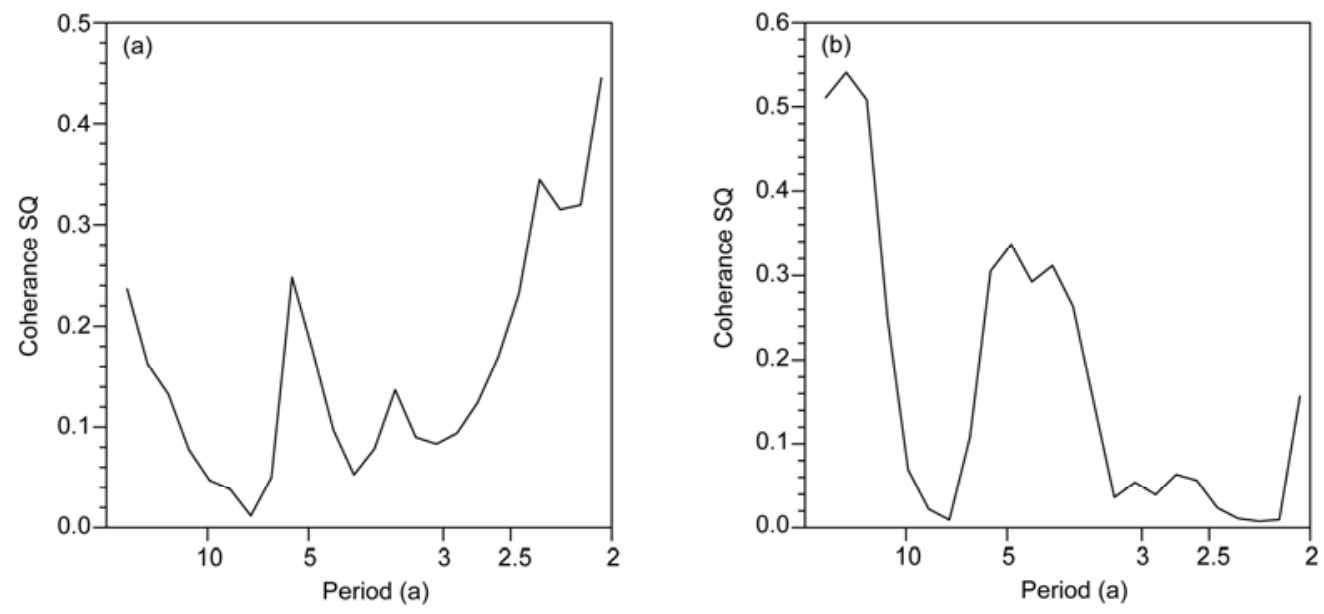

Figure 7 (a) Coherence squared of the North Pacific SSTA $\left(I_{\mathrm{SST}}\right)$ in preceding December and January SAT anomalies over Northeast China, 90\%/95\%/ $99 \%$ significance levels are $0.35 / 0.44 / 0.59$. (b) Same as in (a), except for the coherence squared of the sea ice concentration in the Barents-Kara seas $\left(I_{\text {SIC }}\right)$ and January SAT anomalies over Northeast China.

remote teleconnections over northeast Asia in the downstream region would be anticyclone anomalies from 700 $\mathrm{hPa}$ to $250 \mathrm{hPa}$ for the SIC reduction (see their Figure 4). Thus, the numerical experiments by Petoukhov and Semenov [27] support our results.

\subsection{Comparison of climatic effect of the SSTA and ICE on multiple time-scales}

In the preceding subsection, we analyzed the roles of the North Pacific SSTA and B-K sea ice in the SAT anomalies over NEC. The North Pacific SSTA shows a significant positive correlation with the SAT anomalies in NEC. To explore the climatological impacts of external forcing on the multiple time-scales, we investigated the relationship between the January SAT in NEC and the North Pacific SSTA $\left(I_{\mathrm{SST}}\right)$ by using cross-spectral analysis (Figure 7(a) presents the coherence squared). Careful inspection of the power spectra reveals that the main spectral peaks fall within the 2to 3-year, 3- to 4-year and 10-year periods (Figure 7(a)). The power spectra fall over relatively wide periodicity bands. The spectral estimate contributes $65.5 \%$ to the correlation between the North Pacific SSTA and the SAT anomalies at the interannual time scale, and $24.8 \%$ at the interdecadal time scale. The North Pacific SSTA plays a more important role in the wintertime temperature anomalies over NEC on the interannual time scale than on the interdecadal time scale.

The SIC in the B-K sector shows a significant negative correlation with the January SAT in NEC. We performed a cross-spectral analysis to systematically examine how the relationship between the SAT in NEC and the SIC in the B-K sector $\left(I_{\mathrm{SIC}}\right)$ depends on the time scale (Figure $7(\mathrm{~b})$ presents the coherence squared). Figure 7(b) clearly shows that the SAT anomalies and the $I_{\text {SIC }}$ exhibit a prominent correlation on the interdecadal time scale. The association is not very strong between the SAT anomalies and $I_{\text {SIC }}$ on the interannual time scale. In fact, the spectral estimate accounts for $44 \%$ of the correlation at the interdecadal time scale and for $12.7 \%$ at the interannual time scale. The SIC in the B-K sector exhibits prominent interdecadal variation (figure not shown). The B-K sea ice also experienced a pronounced decrease after 1988, which corresponds to the January SAT interdecadal transition in NEC.

\section{Discussions and conclusions}

We analyzed the anomalous circulations in cases of midwinter (January) temperature anomalies in NEC from 1960- 
2008. We selected cold/warm cases, considering not only the SAT anomalies, but also the duration of low temperature. The most prominent circulation is the cyclonic (anticyclonic) anomaly over northeast Asia, which strengthens (weakens) the northerly flow in the cold (warm) Januarys. We noted the interdecadal as well as the interannual variability of the SAT anomalies in NEC. The January SAT in NEC experienced pronounced warming in the late 1980s, and the circulation shows a similar pattern to the warm cases on the interdecadal time scale.

The North Pacific SSTA and the B-K sea ice in the preceding month are related to the circulation anomalies over northeast Asia. The cold (warm) SST and increased (decreased) SIC may play some important roles in the cold (warm) cases. The cross-spectral analyses indicate that the North Pacific SSTA is more closely associated with the interannual variations of the SAT in NEC. By contrast, there is a strong relationship between the January SAT in NEC and the B-K sea ice concentration on the interdecadal time scale.

The analyses in this study focus on the general characteristics, patterns and precursors to mid-winter SAT anomalies in NEC. Zhao et al. [28] also pointed out that the tropical-North Pacific mode (TNPM) could exert a strong impact on the midlatitude Asian climate. In fact, the indicators for wintertime climate in different areas of China are quite different. For example, the occurrence of heavy snowfall weather over central-eastern China has a closer relationship with the thermal condition over the Asian continent, than with the El Niño-Southern Oscillation and Arctic Oscillation [29]. Thus, further analyses on wintertime climate variability and its influencing factors in different regions of China are quite needed.

The authors thank two anonymous reviewers for their valuable comments and suggestions. Thanks also go to Profs. Li Shuanglin and Luo Dehai for many interesting discussions during the course of this work. This work was supported by the China Meteorological Administration Special Public Welfare Research Fund (GYHY201106015 and GYHY20090614), the National Basic Research Program of China (2009CB421401), and the National Science and Technology Supporting Program of China (2009BAC51B02).

1 Wu B Y, Su J Z, Zhang R H. Effects of autumn-winter Arctic sea ice on winter Siberian High. Chin Sci Bull, 2011, 56: 3220-3228

2 Han Z, Li S, Mu M. The role of warm North Atlantic SST in the formation of positive height anomalies over the Ural Mountains during January 2008. Adv Atmos Sci, 2011, 28: 246-256

3 Fan K. Predicting winter surface air temperature in Northeast China. Atmos Oceanic Sci Lett, 2009, 2: 14-17

4 Liu S, Yang S, Lian Y, et al. Time-frequency characteristics of regional climate over northeast China and their relationships with atmospheric circulation patterns. J Clim, 2010, 23: 4956-4972

5 Jhun J-G, Lee E-J. A new East Asian winter monsoon index and associated characteristics of the winter monsoon. J Clim, 2004, 17: 711-726

6 Gong D Y, Wang S W, Zhu J H. East Asian winter monsoon and Arctic oscillation. Geophys Res Lett, 2001, 28: 2073-2076

7 Wu B Y, Zhang R H, D'Arrigo R. Distinct modes of the East Asian winter monsoon. Mon Weather Rev, 2006, 134: 2165-2179
8 Kang L H, Chen W, Wang L, et al. Interannual variations of winter temperature in China and their relationship with the atmospheric circulation and sea surface temperature (in Chinese). Clim Environ Res, 2009, 14: 45-53

9 Gu L, Wei K, Huang R H. Severe disaster of blizzard, freezing rain and low temperature in January 2008 in China and its association with the anomalies of East Asian monsoon system (in Chinese). Clim Environ Res, 2008, 13: 405-418

10 Trenberth K E, Guillemot C J. Physical processes involved in the 1988 drought and 1993 floods in North America. J Clim, 1996, 9: 1288-1298

11 Zhao P, Zhou X, Jian Z, et al. Modeling the tropical climate and the impact of the western Pacific sea surface temperature at the Last Glacial Maximum. J Geophys Res, 2004, 109: D08105

12 Zhao P, Zhu Y N, Zhang R H. An Asian-Pacific teleconnection in summer tropospheric temperature and associated Asian climate variability. Clim Dyn, 2007, 29: 293-303

13 Li S. Impact of Northwest Atlantic SST anomalies on the circulation over the Ural Mountains during early winter. J Meteor Soc Jpn, 2004, 82: 971-988

14 Bueh C, Ji L R. Anomalous activity of East Asian winter monsoon and the tropical Pacific SSTA (in Chinese). Chin Sci Bull (Chin ver), 1999, 44: 252-259

15 Wu B Y, Wang J, Walsh J. Possible feedback of winter sea ice in the Greenland and Barents Seas on the local atmosphere. Mon Weather Rev, 2004, 132: 1868-1876

16 Ma J H, Wang H J, Zhang Y. Will boreal winter precipitation over China increase in the future? An AGCM simulation under summer "ice-free Arctic" conditions. Chin Sci Bull, 2012, 57: 921-926

17 Wu B Y, Huang R, Gao D Y. Arctic sea ice bordering on the North Atlantic and inter-annual climate variations (in Chinese). Chin Sci Bull (Chin ver), 2000, 46: 162-165

18 Wu B Y, Huang R H, Gao D Y. The impact of variation of sea-ice extent in the Kara Sea and the Barents Seas in winter on the winter monsoon over East Asia (in Chinese). Chin J Atmos Sci, 1999, 23: 267-275

19 Peng S, Mysak L, Ritchie H, et al. The differences between early and midwinter atmospheric responses to sea surface temperature anomalies in the northwest Atlantic. J Clim, 1995, 8: 137-157

20 Kalnay E, Kanamitsu M, Kistler R, et al. The NCEP/NCAR 40-year reanalysis project. Bull Amer Meteor Soc, 1996, 77: 437-471

21 Smith T M, Reynolds R W, Peterson T C, et al. Improvements to NOAA's historical merged land-ocean surface temperature analysis (1880-2006). J Clim, 2008, 21: 2283-2296

22 Rayner N A, Parker D E, Horton E B, et al. Global analyses of sea surface temperature, sea ice, and night marine air temperature since the late nineteenth century. J Geophys Res, 2003, 108: 4407

23 Li Z, Yan Z W. Homogenized daily mean/maximum/minimum temperature series for China from 1960-2008. Atmos Oceanic Sci Lett, 2009, 2: 237-243

24 Roeckner E, Bäuml G, Bonaventura L, et al. The atmospheric general circulation model ECHAM5. Part I: Model description, Rep. 349, Max Planck Inst For Meteorol, Hamburg, Germany, 2003

25 Wang L. Variability of the East Asian trough and its association with the East Winter Monsoon. Dissertation for the Doctoral Degree. Beijing: Institute of Atmospheric Physics, Chinese Academy of Sciences, 2008. 95-111

26 Peng S, Whitaker J S. Mechanisms determining the atmospheric response to midlatitude SST anomalies. J Clim, 1999, 12: 1393-1408

27 Petoukhov V, Semenov V A. A link between reduced Barents-Kara sea ice and cold winter extremes over northern continents. J Geophys Res, 2010, 115: D21111

28 Zhao P, Yang S, Jian M, et al. Relative controls of Asia-Pacific summer climate by Asian land and tropical-North Pacific sea surface temperature. J Clim, 2011, 24: 4165-4188

29 Nan S L, Zhao P. Snowfall over central-eastern China and Asian atmospheric cold source in January. Int J Climatol, 2012, 32: 888-899

Open Access This article is distributed under the terms of the Creative Commons Attribution License which permits any use, distribution, and reproduction in any medium, provided the original author(s) and source are credited. 